\title{
Bridging BIM and building: From a literature review to an integrated conceptual
}

\section{framework}

\section{CHEN K, Lu W, Peng Y, Rowlinson SM, Huang GQ}

\begin{abstract}
A Building Information Model (BIM) is at risk of being 'blind and deaf' if its contained information cannot be synchronized with ongoing building processes in a real-time manner. Previous studies have attempted to explore solutions to the problem, with a view to making BIM a more useful decision-support system. However, an integrated conceptual framework summarizing these studies and structuring future development in the area is missing. Based on an ex post facto critical review of 75 papers of this kind published over the past decade, this paper proposes a conceptual framework for bridging BIM and building (BBB), which highlights the importance of synchronizing information between BIM and real-life building processes. The framework is further illustrated through a case study of prefabricated housing construction in Hong Kong. With this integrated conceptual framework, future research on BBB can proceed on a more solid footing.
\end{abstract}

Keywords: Construction project management; Building Information Modeling (BIM); information and communication technologies; literature review; conceptual framework. 


\section{Introduction}

The importance of information in contemporary construction project management cannot be overemphasized. Managing a construction project involves using available information and knowledge to make a web of decisions across processes including architecture, engineering, construction, and operation (AECO) (Flanagan and Lu, 2008). A comprehensive taxonomy of information in regards to construction project management is yet to be defined; however, it normally comprises building geometry, spatial relationships, and quantities and properties of building components (Pratt, 2004). Lu et al. (2013) identify information as a new element in construction project management, a view which has encouraged the authors' own theoretical stance that a building can, in fact, be perceived of as a cluster of information, the management of which can achieve better AECO performance. It has become a truism that the main objective of information management is to support decision-making by ensuring that accurate information is always available at the right time in the right format to the right person, and it is against this backdrop that the development of Building Information Modeling (BIM) has gained momentum.

According to the U.S. National BIM Standard (2007), BIM is "a digital representation of physical and functional characteristics of a facility and a shared knowledge resource for information about a facility forming a reliable basis for decisions during its life-cycle" 
(p.149). Eastman et al. (2008), on the other hand, intentionally and consistently use the term 'BIM' to describe the activity of modeling building information. In this study, we use 'BIM' to refer to both the activity of modeling and the digital and virtual representation/model of a physical building.

BIM has been adopted by an increasing number of AECO firms to manage project information and support information sharing between stakeholders (Goedert and Meadati, 2008); gradually, it is becoming an indispensable information platform for decision-making in construction. Nevertheless, in current practice, a BIM is largely disconnected from the real-life physical building processes throughout its life-cycle. For example, an architectural or structural model, however it is detailed by architects or engineers, will remain static if the information contained within it cannot be synchronized with the ongoing building process. A BIM is thus at risk of being 'blind and deaf' to ongoing AECO processes, while an 'as-built' model can more reliably and usefully support information exchange and decision-making throughout the project life-cycle. Manually updating information in a BIM in line with the physical building process has been found to be interruptive, tedious ( $\mathrm{Li}$ et al., 2009), time-consuming and error-prone (Anil et al., 2013). To this end, researchers around the world have attempted to develop methods and technologies such as Auto-ID to facilitate the integration of virtual models and physical construction (e.g. Flanagan et al., 2014). 
What seems to be lacking, however, is a conceptual framework highlighting the theoretical perspective of bridging BIM and building (BBB), which means connecting the information contained in BIM with physical building processes to make BIM reflecting real-life situations. Such a framework could help summarize research work in BBB, which has developed in a piecemeal fashion to date. It could also make it possible to theorize a building as a cluster of information; $\mathrm{BBB}$, currently performed via different information and communication technologies (ICTs), has actually become a general research question at the fore of information management (IM) for decision-making in contemporary project management. Further, an integrated conceptual framework would help structure strategic development directions in this area, allowing future research on bridging BIM and building to proceed on a more solid footing.

The aim of this research, therefore, is to develop a conceptual framework that: (1) summarizes the research work related to BBB; (2) highlights the concept of bridging BIM and building; and (3) structures the future directions of research work in this area. It does so by critically reviewing a body of literature comprising 75 papers published in six academic journals over the past decade. Based on the literature review, a conceptual framework is developed and illustrated using a case study. The rest of this paper is structured as follows. The research method of this study is elaborated in Section 2. The results of the literature 
review are presented in Section 3. Based on the results, the conceptual framework for BBB is developed and presented in Section 4. Section 5 is a case study of the use of radio frequency identification (RFID)-enabled BIM in prefabricated housing production in Hong Kong to illustrate the critical issues in BBB. Sections 6 and 7 comprise the discussion and conclusions respectively.

\section{Research methods}

As previous studies have touched upon issues relating to bridging BIM and building (BBB), the development of the conceptual model of BBB starts with a critical literature review. Literature review is defined as "a systematic, explicit, and reproducible method for identifying, evaluating, and interpreting the existing body of recorded work" (Fink, 1998, p.3). It develops the connection between related research works, and helps to identify the current achievement in a specific field and highlight important issues to be solved (Cooper, 1998). Given the difficulty of searching every related research work, delimitation to determine the boundary of the research is often necessary. Here, three criteria were considered during delimitation of the BBB literature:

(1) Only papers in peer-reviewed English journals are reviewed;

(2) The topic of the papers should be strictly limited to the use of virtual models with real-life project information; and

(3) Papers on construction informatics, which describe data acquisition from the physical 
environment but have no relationship to the virtual models, are excluded.

According to our criteria, six journals are selected, namely, International Journal of Project Management, Automation in Construction, ASCE Journal of Construction Engineering and Management, ASCE Journal of Computing in Civil Engineering, Journal of Information Technology in Construction, and Engineering, Construction and Architectural Management. All the six journals have published at least one article fitting the criteria and are highly ranked by construction informatics researchers. The keywords used for searching the relevant papers included 'BIM', 'virtual design and construction (VDC)', 'as-built' model', and 'virtual model'. The contents of each paper were quickly screened by one of the authors to identify whether they should be included or excluded. To decrease potential bias during selection of journal papers, another author double-checked the selected papers. After delimitation, a total of 75 papers published from 2005 to 2014 were identified and considered as recent work.

Preliminary analyses were conducted to determine the basic descriptive information of each selected paper; that is, year of publication, research targets including applications and stages of the project life-cycle, and technologies used to connect the virtual model with physical projects. These descriptive results helped to group the papers before detailed analysis. The advantages and limitations of all possible technologies or methods and their scopes of application were 
critically analyzed with a view to providing components of the conceptual framework of BBB.

The conceptual framework was subsequently evaluated through a case study, feedback from which enhanced the conceptualization of BBB (Fig. 1).

$<<$ Fig. 1 Processes to develop the BBB conceptual framework $>>$

\section{Results of Literature Review}

\subsection{General descriptions of the literature}

The first study hit by the 'selection of papers' is Kim et al. (2005), which explores a rapid modeling method to transform data collected by laser range finder to decision-supporting information in the virtual model. Research relating to bridging BIM and building (BBB) has gained momentum, as witnessed increasing publications after 2005. This upward trend shown in Fig. 2 illustrates a growing recognition of the need to enrich information in a BIM by considering its dynamics with the physical construction project. Researchers have now started to explore models and technologies that can facilitate connection between the virtual and the physical (Flanagan et al., 2014), with a view to making BIM a more helpful decision-support system.

$<<$ Fig. 2 Distribution of selected papers in the past decade $>>$

In these 75 papers, various terms of information model are used other than BIM, such as 
'virtual modeling' (e.g. Lee et al., 2011), 'virtual design and construction' (VDC) (e.g. Mourgues et al., 2012), and '3D modeling' or ' $n \mathrm{D}$ modeling' (e.g. Bansal, 2011; Bhatla et al., 2012; Turkan et al., 2012b; Zhang and Arditi, 2013). This confirms Davies and Harty's (2011) notion that BIM is a common term for a family of technologies and related practices. However, 'BIM' and '3D modeling' are the two most popular terms, adopted by 35 and 34 papers respectively. A convergent use of 'BIM' can be observed (Fig. 3), revealing that after years of debate and promotion BIM is now widely accepted, though a single agreed-upon definition is still lacking.

$<<$ Fig. 3 Percentage of adopted terms from 2005-2009 and 2010-2014>>

\subsection{Detecting elements for the conceptual framework}

The reviewed papers provide supporting elements to this study in its purpose of developing a BBB framework throughout a projects life-cycle. The framework is currently conceptual, however, the reviews of practical technologies and existing preconditions make our framework not only practical but also enlightening.

\subsubsection{Target applications of BBB}

As shown in Fig. 4, 'process tracking' and 'generating 'as-built' models' are the top two applications. For example, Azimi et al. (2011) stored the status information of steel 
components in radio frequency identification (RFID) tags, this information was then returned to the $3 \mathrm{D}$ model so that managers can track the actual process of construction work. Lee et al. (2013b) developed algorithms to automatically build a 3D model of entire pipelines based on laser-scan data. Notably, 'safety management' and 'facilities management' are not prevailing applications of $\mathrm{BBB}$ in the selected papers, although these have been much advocated recently (Ding et al., 2014). One may notice that the total number of applications is larger than 75 (Fig. 4). This is due to the fact that some studies consider more than one target application. For example, the study carried out by Bosché and Guenet (2014) used laser scanner to generate an 'as-built' model and control the quality of construction works.

$<<$ Fig. 4 Distribution of target applications of $\mathrm{BBB}>>$

\subsubsection{Project stages for BBB applications}

As shown in Fig. 5, about $70 \%$ of the selected papers study applications at the construction stage. This should not come as a surprise; construction is the stage that takes the information from design and materializes a project. It is also the stage that needs information for intensive decision-making. Eight papers study the post-construction stage, at which an 'as-built' model is developed before operation and maintenance has begun. In contrast, only 3 papers considered the integration of virtual models (BIM, 3D model or others) and real-life data for wider applications throughout project life-cycle. 
$<<$ Fig. 5 Project stages for BBB applications $>>$

\subsubsection{Technologies for BBB}

Fig. 6 depicts the distribution of introduced technologies for data acquisition from real-life processes and integration between virtual models and physical building. There are eight types of technologies in total, amongst which laser scanning, radio frequency identification (RFID), and camera are the most popular technologies proposed for BBB. Other related technologies include augmented reality (AR), geographic information system (GIS), global positioning system (GPS), and sensor.

$<<$ Fig. 6 Technologies adopted $>>$

\subsubsection{Laser Scanning}

Laser scanning which is adopted in 28 studies digitally captures geometric data and spatial relationships through laser light (Shih and Huang, 2006). As shown in Table 1, it is mainly used for process tracking (e.g. Turkan et al., 2012a) and 'generation of 'as-built' models' (e.g. Arayici, 2007; Tang et al., 2010; Jung et al., 2014). Deviations between the 'as-built' and 'as-designed' models are used to assess the quality of construction work (Akinci et al., 2006). Besides, the spatial data of specific objects support site monitoring (Su et al., 2006), resources tracking (Teizer et al., 2007), and safety management (Cheng and Teizer, 2013). 
$<<$ Table 1 Applications of laser scanning $>>$

According to the studies, current BBB practice using laser scanning is heavily reliant on manual effort (Anil et al., 2011; Brilakis et al., 2011). Some researchers present approaches and algorithms that can achieve automatic object identification (Bosché et al., 2013; Xiong et al., 2013) and improve object recognition quality (Bosché et al., 2009), and flash LADAR technology enables rapid scanning for highly active situations (Randall, 2011).

\subsubsection{Auto-ID technology}

The use of Auto-ID technology such as 2D barcode and RFID, in the construction industry is not new. Twenty papers adopt RFID for the acquisition of real-life information and integration with the virtual model for the seven applications shown in Table 2.

$<<$ Table 2 Applications of RFID $>>$

It is found that RFID is suitable for tracking the process of projects where steel (Xie et al., 2011) or prefabricated components (Lu et al., 2011) are used. In addition, RFID facilitates updating material properties and component inventories in the virtual model, which enhances quality control and supply chain management (Sørensen et al., 2009). Real-time locations of workers, equipment and facilities that are tracked and recorded by RFID support safety 
management (Park and Kim, 2013; Ding et al., 2013), activity monitoring (Azimi et al., 2011;

Shahi et al., 2013) and facility management (Shen et al., 2012).

\subsubsection{Camera}

Table 3 shows the main applications of camera for BBB. It has been used to rapidly detect and track static and moving objects including workers and equipment at the construction site (Son and Kim, 2010; Son et al., 2010; Park and Brilakis, 2012). Based on photos taken from different positions and angles, a 'real-life' model can be developed (Dai and Lu, 2010). This model can then be used to calculate the percentage of completion and track the actual construction process (Golparvar-Fard et al., 2009; El-Omari and Moselhi, 2011; Roh et al., 2011). Cameras collect real-life information at a lower cost and with less computational time than laser scanners (Kim et al., 2013), but their accuracy is less in complex environments (Klein et al., 2012). Some researchers have attempted to integrate laser scanning and photogrammetry to overcome the limitations of each (El-Omari and Moselhi, 2008; Zhu and Brilakis, 2009; Dai et al. 2012).

$<<$ Table 3 Applications of camera $>>$

\subsubsection{Augmented reality}

Unlike the other technologies listed in Fig. 7, augmented reality (AR) does not capture 
physical information and import it into a virtual model; conversely, it displays virtual information in a real-world environment (Yeh et al., 2012; Jiao et al., 2013; Wang et al., 2013). With the help of AR, the as-planned model can be vividly shown at the physical construction site to act as a baseline for process tracking (Kamat et al., 2010) and monitor construction performance (Park et al., 2013; Lee, et al., 2013a; Kwon et al., 2014). In addition, AR provides instruction for workers, helping them to understand the as-planned progress (Wang et al., 2014a). AR is thus a preferred and unique technology for BBB.

\subsubsection{Global Positioning System and Geographic Information System}

Global positioning system (GPS) is the most common tool for outdoor localization and tracking (Taneja et al., 2010). In the selected papers, GPS provides geo-references for retrieval of virtual elements from scanned data (Bosché and Haas, 2007), and can be used in conjunction with RFID to provide location information for construction components (Torrent and Caldas, 2009; Vähä, 2013) or materials (Razavi and Haas, 2010). A geographic information system (GIS) can support the analysis of huge amounts of spatial data (Bansal and Pal, 2008), which in conjunction with BIM can determine the feasible areas for tower cranes to cover all demand and supply points (Irizarry and Karan, 2012) and visually

illustrate the flow of material in supply chain management (Irizarry et al., 2013b). Additionally, building 3D models in a GIS environment enhances understanding of project schedules (Poku and Arditi, 2006; Bansal and Pal, 2009). 


\subsubsection{Sensor}

Various types of sensor are adopted to collect real-life information including the quality of cast-in-place concrete elements (Akinci et al., 2006), the safety status of underground environments (Ding et al., 2013), and the real-time temperature and oxygen values in a confined working space (Riaz et al., 2014). This real-time information can be transferred to a BIM via wireless network and presented in the visual environment, significantly improving the effectiveness of construction project management.

\subsubsection{Software, database, and information exchange protocols}

Most of the selected papers do not provide information about 3D model or BIM development software. Among those mentioning the software for developing 3D model or BIM, 18 papers adopt Autodesk ${ }^{\circledR R e v i t}{ }^{\circledR} \quad$ (e.g. Wang et al., 2014b), while 6 and 5 studies use Bentley ${ }^{\circledR}$ MicroStation ${ }^{\circledR}$ and Graphisoft ${ }^{\circledR} A r c h i C A D \circledR$ respectively (e.g. Bosché and Haas, 2008; Chin et al., 2008). SketchUp is used by 2 studies (e.g. Teizer et al., 2013) to draw 3D models. Tekla or Autodesk ${ }^{\circledR} 3 \mathrm{ds}$ Max ${ }^{\circledR}$ can model typical building components. For project reviewing, Autodesk ${ }^{\circledR N a v i s w o r k s}{ }^{\circledR}$ and Bentley ${ }^{\circledR N a v i g a t o r}(\AA)$ are adopted in a few papers (e.g. Zhou et al., 2013; Goedert and Meadati, 2008). As regards databases, 7 papers adopt one among SQL Server, MySQL, and Microsoft Access (e.g. Chin et al., 2008; Motamedi and Hammad, 2009; El-Omari and Moselhi, 2009). The connection between the database and 3D 
model or BIM software is developed by Application Programming Interface (API) which is programmed by either VB.Net, C\# or C++ (e.g. Goedert and Meadati, 2008; Riaz et al., 2014).

The format of information affects the possibility and quality of information exchange. After generating a 3D model or BIM using the software mentioned above, the model is set or transferred to the desired format (e.g. FBX, DWG, STL, 3DS, DXF, IFC) in order to connect it with other software such as Matlab® (Son and Kim, 2010) and ArcView (Poku and Arditi, 2006). For instance, models developed by Bentley®MicroStation ${ }^{\circledR}$ are exported into STL format before integration with data collected by laser scanner (Bosché and Haas, 2008). IFC format provides an appropriate structure for information sharing (Vanlande et al., 2008) and is applied in most of the selected papers to increase interoperability (e.g. Boukamp and Akinci, 2007; Motamedi and Hammad, 2009). Eight papers adopt XML-based format as it can be shared by proper XML interfaces (Irizarry et al., 2013a; Lagüela et al., 2013).

\subsection{Summary}

The critical literature review provided several insights:

(1) Given that an information-rich BIM can facilitate decision-making in the building process, the attention has increasingly been paid to bridging BIM and building (BBB); 
(2) No integrated conceptual framework that summarizes existing research in this area and structures future strategic directions has been proposed;

(3) Most of the selected papers are concerned with 'tracking' and 'generation of an as-built model' at construction stage, while wider applications of BBB at other project stages are yet to be explored;

(4) None of the BBB technologies explored in previous studies can satisfy all needs arising throughout a project life-cycle, and software, database, and data exchange protocol issues should be paid more consideration during the course.

(5) There is a general lack of studies on interoperability of data among different BIM software programs and hard data-acquisition technologies.

(6) A collaboration of various technologies could facilitate integration of building information models and physical building processes.

Based on the insights, a framework supporting research and practice is proposed.

\section{The conceptual framework for bridging BIM and building}

The conceptual framework, as shown in Fig. 7, has three major layers, namely the physical layer, the central database/gateway layer, and the BIM layer.

(1) The physical layer

The physical layer consists of a series of activities ranging from site investigation to demolition following a project lifecycle. Most of these activities require many inputs 
including time, money, material, and manpower. Meanwhile, they generate various types of information to be detected, collected and retrieved in a timely manner to support decision-making. A collaboration of technologies as introduced in Section 3.2.3 are arranged to acquire all project-relevant data. Lines drawn between the technology and the physical activity indicate the data acquisition.

(2) The central database/gateway layer

In the central database/gateway layer, the information collected throughout the project processes by different technologies is stored, and its format is transferred to work in BIM environment. This layer is of crucial importance for the reason that it ensures the interoperability of information. Besides, the stored information must be secure, thus only authorized stakeholders can access it.

(3) The BIM layer

The BIM layer involves a shared model developed in the design stage, it finally presented the real-life information for stakeholders to conduct a series of decision-making. The information is grouped by type and linked with the digital components in BIM.

Considering each part of the conceptual framework is not always at the same location, all information in digital format is transferred through network. Amongst available 
communication networks, a local area network (LAN) can interconnect computers in the construction site and support information transfer within a group, while a personal area network (PAN), including Bluetooth and ZigBee, mainly serves individuals over short distances.

$<<$ Fig. 7 The conceptual framework for bridging BIM and building $>>$

\section{Case study}

A case study has been adopted to illustrate the practical uses of the conceptual framework for bridging $\mathrm{BIM}$ and building (BBB). The case concerns prefabricated housing production in Hong Kong. The developer aims to achieve better time, quality, cost, safety, and environmental records by improving the process using the latest technological instruments such as BIM and Auto-ID. The process comprises an array of decisions to be made, and the developer desires real-time information so that it can make informed decisions and thus achieve its goals. BIM is expected to be the ideal platform to provide this information if it can be synchronized with the prolonged process of prefabricated housing production. A research team was tasked to develop such platform, which includes a large number of sub decision support systems. From the outset, the research team was aware of the existence of studies of this kind but they are in a piecemeal fashion. It was determined to understand the production process, streamlining it, and examining the availability and suitability of technologies first, 
instead of designing the system architecture hastily. The BBB conceptual framework provides the footing for analysis of this process and exploration of potential technical solutions.

\subsection{Design stage}

In this project, the design team depart from conventional practice to design directly using BIM. The design has suitable Level of Development (LOD) (e.g. LOD 350) that strikes balance between information sufficiency and BIM 'thinness'. After the completion of design in the BIM environment, a list of prefabricated components and their quantities are extracted from the model and used to purchase the components.

\subsection{Manufacturing stage}

Detailed design information for the precast elements contained in the BIM is communicated to the manufacturers for prefabrication production. Auto-ID technologies are adopted at this stage to turn all the components into Smart Construction Objects (SCO) (Huang et al., 2008), with a view to bridging the information between the objects and the BIM. Given its strengths (Lu et al., 2011), radio frequency identification (RFID) is adopted as the 'bridging' technology in this case study. Clients and manufacturers explore proper RFID models (e.g. active or passive, and suitable radio frequency) and standards when embedding RFID tags in the precast components (See Fig. 8). 
$<<$ Fig. 8 Building components with RFID tags $>>$

The positions of the tags are indicated in the BIM in order to achieve standardized production.

A unique identification number, regulated by a pre-defined naming convention, is set in the tag in order to register the precast components in the central database and link this information with the digital BIM. Tests are arranged to check whether the quality of the precast components can meet the project's requirements. Results are transferred to central database where they are automatically grouped. It is confirmed by the director of the manufacturing company that RFID and the central database offer much convenience for information management than conventional paper-based method.

For precast components meeting the quality requirements, they are properly stored in the yard before delivery. The components are scanned by RFID readers which change the status of components from "Manufacturing" to "In storage" and update such information in the database. Since the components are linked with the digital representation in BIM, the client and the contractor in Hong Kong can remotely monitor the status of the precast components in the BIM, i.e. real-time information visibility and traceability.

\subsection{Delivery stage}


The schedule of delivery is developed based on the 'as-planned' project schedule embedded in the BIM. In this project, a third-party logistics company is responsible for component delivery. Before precast components are loaded onto the truck, the embedded RFID tags are read in order to ensure that the right elements are delivered. Meanwhile, status of those components change from "In storage" to "Delivery" in the database. The client and the contractor in Hong Kong can click on the virtual components in BIM to find out which have been delivered. Once the truck arrives on site, after damage checking, the status changes from "Delivery" to "Received".

\subsection{On-site assembly stage}

At installation, workers use handheld RFID readers to scan the tags of the prefabricated components to get the 'as-design' locations in the BIM, which guarantees that no prefabricated component will be installed at the wrong location. Given that these are high-rise buildings in Hong Kong, GIS and AR Drone technologies are adopted to provide real-time site information for the installation work. When a component is installed, a worker scans the embedded RFID tag and updates the status from "Received" to "Installed" in both the database and the BIM. The contractor can refer to the status of each component in the virtual model to gain information about the real-time construction process. In this case, the client's ambition is to achieve 'Just-in-time (JIT)' delivery and onsite assembly. The narrow streets and confined site areas in Hong Kong necessitate a JIT operation but, together with the 
prolonged logistic and supply chain, add to the difficulties of doing so.

\subsection{Operation and maintenance stage}

Although this case is still at the construction stage, it is expected that the 'as-built' BIM, developed by BBB, will be passed on to later stages for building operation and maintenance (O\&M). In this project, all components have been installed with RFID tags for identification and tracking and have been connected to the corresponding virtual BIM. One facility can be easily differentiated from others, and facility managers can quickly obtain the exact location of components from the model for periodical inspection, analysis, and maintenance if a problem is discovered. Sensors will also be used to monitor performance and capture operation data. Information such as the amount of water or electricity usage will be accurately recorded in the central database to facilitate O\&M.

\subsection{Experience learnt for the case study}

The conceptual framework does not demanded the integration of the individual construction processes such as design, bid, manufacturing, and build, which might be constrained by practical situations, e.g. bidding is often mandated by authority if this is a project funded by the public sector. Instead, the framework proposes various technologies that can capture real-life information from the physical world, with a view to alleviating the fragmentation and discontinuity existing in existing construction processes. The conceptual framework also 
lists the possible functions if BIM is adequately enriched with information through BBB.

This framework is thus becoming an intuitive tool for mainstreaming the use of BIM and information management; stakeholders well understood their positions in the framework and the potential contributions they can make.

Back to the system development level, the research team has hugely benefited from the conceptual framework. For example, it helped us to analyze the construction project processes, with a flexibility to be modified for either cast in-situ or prefabrication, either for building or other types of projects. A significant and innovative contribution when developing and applying the conceptual framework is to propose a gateway. Nowadays information is collected through different technologies with different formats (e.g. photos, numbers) and different operational systems (e.g. Windows, OS, and Android); with the gateways, the system can deal with the heterogeneous BBB technologies before the information is stored in the database and transferred to BIM. The conceptual framework, with proper modifications, has been used to develop architectures of real RFID-enabled BIM systems for prefabricated housing production.

\section{Discussion}

The conceptual framework can serve as the foundation for enriched BIM and facilitate construction project management. BIM has the potential to be the catalyst for project 
managers to reengineer their processes to better integrate the different stakeholders involved in modern construction projects (Bryde et al., 2013). This conceptual framework, informed by the many studies in this field, further highlights the importance of bridging BIM and building (BBB) in this catalyst taking effect. The framework echoes the concept of a cyber-physical system for coordination of virtual models and physical construction introduced by Akanmu et al. (2013) and Flanagan et al. (2014), although such a system has not yet been tested in a real-world situation.

The BBB framework in the above case can be further understood by linking it with the information systems prevailing in the manufacturing industry, given the similarities between prefabrication construction and manufacturing. For example, Huang et al. (2011) developed a conceptual Gateway Product Service System (iGPSS) framework for cost-effective deployment of RFID-enabled manufacturing solutions. Its system structure and the three key components, which can be a very useful reference point if the BBB framework is to be operationalized in prefabrication construction. Where the heterogeneity of a construction project (e.g. fixed job site, and one-off and complex nature) is concerned, the BBB framework can be further comprehended in conjunction with the Open Systems Interconnection model (OSI), which is a conceptual model widely used in structuring the Internet or other communication systems. The OSI characterizes and standardizes the internal 
functions of a communication system by partitioning it into abstraction layers (Day and Zimmermann, 1983). The multi-layer structure of the BBB conceptual framework is similar to that of the OSI.

The conceptual framework integrates stakeholders throughout the project life-cycle, delineating different information and communication technologies (ICTs) and their associated software, database, and information exchange protocols to make BIM more useful. The framework is thus a powerful tool for practitioners to mainstream their BIM implementation strategies. Notably, the BIM-related software vendor RIB Group has developed a similar framework to introduce its platform iTWO, which can be understood as an information exchange platform between the virtual and the physical in a construction project, and amongst the different stakeholders who are involved in the project (König et al., 2012).

Although investigation of the technologies that can link the virtual model and the physical construction process is nothing new, one of the significant contributions of the integrated framework is to highlight the general conception of BBB. Researchers can theorize bridging BIM and building by linking the area to the general theories of information management while considering the characteristics of project-based organization (e.g. Söderlund, 2004; 
Morris et al., 2011). Researchers can also further explore the practical uses of BBB technologies that can make BIM a more useful decision support system. In any case, the developed conceptual BBB framework can serve as solid footing for future research.

\section{Conclusions}

Researchers over the years have published studies exploring methods and technologies for capturing real-time information from real-life physical project processes and synchronizing it with BIM as a central information platform. These efforts are conceptualized as 'bridging BIM and building (BBB)', which has become a general research question at the frontier of information management for decision-making in contemporary project management. A critical review of existing studies showed that they mainly concern 'tracking' and 'generation of an 'as-built' model' at construction stage, while wider applications of BBB at other stages are yet to be considered. The major technologies explored were laser scanning, RFID, camera, GIS, GPS, and AR. To date, software, databases, and data exchange protocols have been paid scant attention in BBB studies. Collaboration of various technologies could integrate building information models and physical building processes for better project management performance.

Building on the literature review, this study has developed an integrated conceptual framework for BBB. The framework comprises several layers, including a physical layer 
(representing the actual architecture, engineering, construction, and operation [AECO] activities throughout a project life-cycle), BBB technologies, a BIM layer, and the central database set up between the physical layer and the BIM layer. It can be used by practitioners as a powerful tool for mainstreaming or planning their BIM implementation strategies with a view to improving project management performance. Future research is recommended into theorizing $\mathrm{BBB}$ by linking it to the general theories of information management and the characteristics of construction projects and project-based organizations. Researchers are also recommended to further explore the practical uses of BBB technologies that can make BIM a more useful decision-support system. With this integrated conceptual framework, future research on $\mathrm{BBB}$ can proceed on a more solid footing.

\section{Acknowledgement}

This study is jointly supported by the Innovation and Technology Fund (Project No.: ITP/045/13LP) of the Hong Kong Innovation and Technology Commission (ITC), and the General Research Fund (Project No.: 17205614) of the Hong Kong Research Grant Council (RGC).

\section{References}

Akanmu, A., Anumba, C., and Messner, J. 2013. Scenarios for cyber-physical systems integration in construction. Journal of Information Technology in Construction (ITcon), $18,240-260$. 
Akinci, B., Boukamp, F., Gordon, C., Huber, D., Lyons, C., and Park, K. 2006. A formalism for utilization of sensor systems and integrated project models for active construction quality control. Automation in Construction, 15(2), 124-138.

Anil, E. B., Tang, P., Akinci, B., and Huber, D. 2011. Assessment of Quality of As-is Building Information Models Generated from Point Clouds Using Deviation Analysis. In Proceedings of the SPIE Vol. 7864A, Electronics Imaging Science and Technology Conference (IS\&T).

Anil, E. B., Tang, P., Akinci, B., and Huber, D. 2013. Deviation analysis method for the assessment of the quality of the as-is Building Information Models generated from point cloud data. Automation in Construction, 35, 507-516.

Arayici, Y. 2007. An approach for real world data modelling with the 3D terrestrial laser scanner for built environment. Automation in Construction, 16(6), 816-829.

Azimi, R., Lee, S., AbouRizk, S. M., and Alvanchi, A. 2011. A framework for an automated and integrated project monitoring and control system for steel fabrication projects. Automation in Construction, 20(1), 88-97.

Bansal, V. 2011. Application of geographic information systems in construction safety planning. International Journal of Project Management, 29(1), 66-77.

Bansal, V. and Pal, M. 2008. Generating, evaluating, and visualizing construction schedule with geographic information systems. Journal of Computing in Civil Engineering ASCE, 22(4), 233-242.

Bansal, V. and Pal, M. 2009. Construction schedule review in GIS with a navigable 3D animation of project activities. International Journal of Project Management, 27(5), $532-542$.

Bhatla, A., Choe, S. Y., Fierro, O., and Leite, F. 2012. Evaluation of accuracy of 'as-built' 3D modeling from photos taken by handheld digital cameras. Automation in Construction, 
$28,116-127$.

Bosché, F. and Haas, C. 2007. Towards automated retrieval of 3D designed data in 3D sensed data. In Proceedings of the 2007 ASCE International Workshop on Journal of Computing in Civil Engineering.

Bosché, F. and Guenet, E. 2014. Automating surface flatness control using terrestrial laser scanning and building information models. Automation in Construction, 44, 212-226.

Bosché, F. and Haas, C. 2008. Automated retrieval of 3D CAD model objects in construction range images. Automation in Construction, 17(4), 499-512.

Bosché, F., Guillemet, A., Turkan, Y., Haas, C. T., and Haas, R. (2013). Tracking the Built Status of MEP Works: Assessing the Value of a Scan-vs.-BIM System. Journal of Computing in Civil Engineering ASCE.

Bosché, F., Haas, C. T., and Akinci, B. 2009. Automated recognition of 3D CAD objects in site laser scans for project 3D status visualization and performance control. Journal of Computing in Civil Engineering ASCE, 23(6), 311-318.

Boukamp, F. and Akinci, B. 2007. Automated processing of construction specifications to support inspection and quality control. Automation in Construction, 17(1), 90-106.

Brilakis, I., Fathi, H., and Rashidi, A. 2011. Progressive 3D reconstruction of infrastructure with videogrammetry. Automation in Construction, 20(7), 884-895.

Bryde, D., Broquetas, M., and Volm, J. M. 2013. The project benefits of Building Information Modelling (BIM). International Journal of Project Management, 31(7), 971-980.

Cheng, T. and Teizer, J. 2013. Real-time resource location data collection and visualization technology for construction safety and activity monitoring applications. Automation in Construction, 34, 3-15.

Chin, S., Yoon, S., Choi, C., and Cho, C. 2008. RFID+ 4D CAD for progress management of structural steel works in high-rise buildings. Journal of Computing in Civil Engineering 
ASCE, 22(2), 74-89.

Cooper, H. 1998. Synthesizing research: A guide for literature reviews. (3rd ed.). Beverly Hills, CA: Sage.

Dai, F. and Lu, M. 2010. Assessing the accuracy of applying photogrammetry to take geometric measurements on building products. Journal of Construction Engineering and Management ASCE, 136(2), 242-250.

Dai, F., Rashidi, A., Brilakis, I., and Vela, P. 2012. Comparison of image-based and time-of-flight-based technologies for three-dimensional reconstruction of infrastructure. Journal of Construction Engineering and Management ASCE, 139(1), 69-79.

Davies, R. and Harty, C. 2011. Building Information Modelling as innovation journey: BIM experiences on a major UK healthcare infrastructure project. In 6th Nordic Conference on Construction Economics and Organisation - Shaping the Construction / Society Nexus.

Day, J. D. and Zimmermann, H. 1983. The OSI reference model. In Proceedings of the IEEE, 71(12), 1334-1340.

Ding, L., Zhou, C., Deng, Q., Luo, H., Ye, X., Ni, Y., and Guo, P. 2013. Real-time safety early warning system for cross passage construction in Yangtze Riverbed Metro Tunnel based on the Internet of Things. Automation in Construction, 36, 25-37.

Ding, L., Zhou, Y., and Akinci, B. 2014. Building Information Modeling (BIM) application framework: The process of expanding from 3D to computable nD. Automation in Construction, 46, 82-93.

Eastman, C., Teicholz, P., Sacks, R., and Liston, K. 2008. BIM Handbook: A Guide to Building Information Modeling for Owners, Managers, Designers, Engineers and Contractors, NY: John Wiley and Sons.

El-Omari, S. and Moselhi, O. 2008. Integrating 3D laser scanning and photogrammetry for 
progress measurement of construction work. Automation in Construction, 18(1), 1-9.

El-Omari, S. and Moselhi, O. 2009. Data acquisition from construction sites for tracking purposes. Engineering, Construction and Architectural Management, 16(5), 490-503.

El-Omari, S. and Moselhi, O. 2011. Integrating automated data acquisition technologies for progress reporting of construction projects. Automation in Construction, 20(6), 699-705.

Fink, A. 1998. Conducting research literature reviews: from paper to the Internet. London: Sage Publications.

Flanagan, R., Jewell, C, Lu, W. S. and Pekericli, K. 2014. Auto-ID - Bridging the physical and the digital on construction projects. Chartered Institute of Building. ISBN 1853800191.

Flanagan, R. and Lu, W. S. 2008. Making informed decisionsin product-service systems. IMechE Conference, Knowledge and Information Management Through-Life, Institute of Mechanical Engineers.

Goedert, J. D. and Meadati, P. 2008. Integrating construction process documentation into building information modeling. Journal of Construction Engineering and Management ASCE, 134(7), 509-516.

Golparvar-Fard, M., Peña-Mora, F., Arboleda, C. A., and Lee, S. 2009. Visualization of construction progress monitoring with 4D simulation model overlaid on time-lapsed photographs. Journal of Computing in Civil Engineering ASCE, 23(6), 391-404.

Huang, G. Q., Qu, T., Fang, M. J., and Bramley, A.N. 2011. RFID-enabled gateway product service system for collaborative manufacturing alliances. CIRP Annals - Manufacturing Technology, 60(1), 465-468.

Huang, G. Q., Zhang, Y. F., and Jiang, P. Y. 2008. RFID-based wireless manufacturing for real-time management of job shop WIP inventories, International Journal of Advanced Manufacturing Technology, 36(7-8), 752-764. 
Irizarry, J. and Karan, E. P. 2012. Optimizing location of tower cranes on construction sites through GIS and BIM integration. Journal of Information Technology in Construction (ITcon), 17, 351-366.

Irizarry, J., Gheisari, M., Williams, G., and Walker, B. N. 2013a. InfoSPOT: A mobile Augmented Reality method for accessing building information through a situation awareness approach. Automation in Construction, 33, 11-23.

Irizarry, J., Karan, E. P., and Jalaei, F. 2013b. Integrating BIM and GIS to improve the visual monitoring of construction supply chain management. Automation in Construction, 31, 241-254.

Jiao, Y., Zhang, S., Li, Y., Wang, Y., and Yang, B. 2013. Towards cloud Augmented Reality for construction application by BIM and SNS integration. Automation in Construction, $33,37-47$.

Jung, J., Hong, S., Jeong, S., Kim, S., Cho, H., Hong, S., and Heo, J. 2014. Productive modeling for development of 'as-built' BIM of existing indoor structures. Automation in Construction, 42, 68-77.

Kamat, V. R., Martinez, J. C., Fischer, M., Golparvar-Fard, M., Peña-Mora, F., and Savarese, S. 2010. Research in visualization techniques for field construction. Journal of Construction Engineering and Management ASCE, 137(10), 853-862.

Kim, C., Haas, C. T., and Liapi, K. A. 2005. Rapid, on-site spatial information acquisition and its use for infrastructure operation and maintenance. Automation in Construction, 14(5), 666-684.

Kim, C., Kim, B., and Kim, H. 2013. 4D CAD model updating using image processing-based construction progress monitoring. Automation in Construction, 35, 44-52.

Klein, L., Li, N., and Becerik-Gerber, B. 2012. Imaged-based verification of 'as-built' documentation of operational buildings. Automation in Construction, 21, 161-171. 
König, M., Koch, C., Habenicht, I., and Spieckermann, S. 2012. Intelligent BIM-based construction scheduling using discrete event simulation. In Proceedings of the Winter Simulation Conference. IEEE.

Kwon, O. S., Park, C. S., and Lim, C.R. 2014. A defect management system for reinforced concrete work utilizing BIM, image-matching and augmented reality. Automation in Construction. 46, 74-81.

Lagüela, S., Díaz-Vilariño, L., Martínez, J., and Armesto, J. 2013. Automatic thermographic and RGB texture of 'as-built' BIM for energy rehabilitation purposes. Automation in Construction, 31, 230-240.

Lee, H. S., Lee, K. P., Park, M., Baek, Y., and Lee, S. 2011. RFID-based real-time locating system for construction safety management. Journal of Computing in Civil Engineering ASCE, 26(3), 366-377.

Lee, J., Jeong, Y., Oh, Y. S., Lee, J. C., Ahn, N., Lee, J., and Yoon, S. H. 2013a. An integrated approach to intelligent urban facilities management for real-time emergency response. Automation in Construction, 30, 256-264.

Lee, J., Son, H., Kim, C., and Kim, C. 2013b. Skeleton-based 3D reconstruction of 'as-built' pipelines from laser-scan data. Automation in Construction, 35, 199-207.

Li, H., Lu, W. S., and Huang, T. 2009. Rethinking project management and exploring virtual design and construction as a potential solution. Construction Management and Economics, 27(4), 363-371.

Lu, W. S., Huang, G. Q., and Li, H. 2011. Scenarios for applying RFID technology in construction project management. Automation in Construction, 20(2), 101-106.

Lu, W. S., Peng, Y., Shen, Q. P., and Li, H. 2013. A generic model for measuring benefits of BIM as a learning tool in construction tasks. Journal of Construction Engineering and Management ASCE, 139(2), 195-203. 
Morris, P. W. G., Pinto, J. K., and Söderlund, J. 2011. The Oxford Handbook of Project Management, Oxford University Press.

Motamedi, A. and Hammad, A. 2009. Lifecycle management of facilities components using radio frequency identification and building information model. Journal of Information Technology in Construction (ITcon), 14(Special Issue), 238-262.

Mourgues, C., Fischer, M., and Kunz, J. 2012. Method to produce field instructions from product and process models for cast-in-place concrete operations. Automation in Construction, 22, 233-246.

National BIM Standard. 2007. National Institute of Building Sciences.

Park, C. S. and Kim, H. J. 2013. A framework for construction safety management and visualization system. Automation in Construction, 33, 95-103.

Park, C. S., Lee, D. Y., Kwon, O. S., and Wang, X. 2013. A framework for proactive construction defect management using BIM, augmented reality and ontology-based data collection template. Automation in Construction, 33, 61-71.

Park, M. W. and Brilakis, I. 2012. Construction worker detection in video frames for initializing vision trackers. Automation in Construction, 28, 15-25.

Poku, S. E. and Arditi, D. 2006. Construction scheduling and progress control using geographical information systems. Journal of Computing in Civil Engineering ASCE, 20(5), 351-360.

Pratt, M. J. 2004. Extension of ISO 10303, the STEP standard, for the exchange of procedural shape models. In Proceedings of Shape Modeling Applications, 317-326. IEEE.

Randall, T. 2011. Construction engineering requirements for integrating laser scanning technology and building information modeling. Journal of Construction Engineering and Management ASCE, 137(10), 797-805.

Razavi, S. N. and Haas, C. T. 2010. Multisensor data fusion for on-site materials tracking in 
construction. Automation in Construction, 19(8), 1037-1046.

Riaz, Z., Arslan, M., Kiani, A. K., and Azhar, S. 2014. CoSMoS: A BIM and wireless sensor based integrated solution for worker safety in confined spaces. Automation in Construction, 45, 96-106.

Roh, S., Aziz, Z., and Peña-Mora, F. 2011. An object-based 3D walk-through model for interior construction progress monitoring. Automation in Construction, 20(1), 66-75.

Shahi, A., West, J. S., and Haas, C. T. 2013. Onsite 3D marking for construction activity tracking. Automation in Construction, 30, 136-143.

Shen, W., Hao, Q., and Xue, Y. 2012. A loosely coupled system integration approach for decision support in facility management and maintenance. Automation in Construction, $25,41-48$.

Shih, N. J. and Huang, S. T. 2006. 3D scan information management system for construction management. Journal of Construction Engineering and Management ASCE, 132(2), $134-142$.

Söderlund, J. 2004. Building theories of project management: past research, questions for the future. International Journal of Project Management, 22, 183-191.

Son, H. and Kim, C. 2010. 3D structural component recognition and modeling method using color and 3D data for construction progress monitoring. Automation in Construction, 19(7), 844-854.

Son, H., Kim, C., and Choi, K. 2010. Rapid 3D object detection and modeling using range data from 3D range imaging camera for heavy equipment operation. Automation in Construction, 19(7), 898-906.

Sørensen, K. B., Christiansson, P., and Svidt, K. 2009. Prototype development of an ICT system to support construction management based on virtual models and RFID. Journal of Information Technology in Construction (ITcon), 14(Special Issue), 263-288. 
Su, Y., Hashash, Y., and Liu, L. 2006. Integration of construction 'as-built' data via laser scanning with geotechnical monitoring of urban excavation. Journal of Construction Engineering and Management ASCE, 132(12), 1234-1241.

Taneja, S., Akinci, B., Garrett, J. H., Soibelman, L., Ergen, E., Pradhan, A., Liu, X. 2010. Sensing and field data capture for construction and facility operations. Journal of Construction Engineering and Management ASCE, 137(10), 870-881.

Tang, P., Huber, D., Akinci, B., Lipman, R., and Lytle, A. 2010. Automatic reconstruction of 'as-built' building information models from laser-scanned point clouds: A review of related techniques. Automation in Construction, 19(7), 829-843.

Teizer, J., Caldas, C. H., and Haas, C. T. 2007. Real-time three-dimensional occupancy grid modeling for the detection and tracking of construction resources. Journal of Construction Engineering and Management ASCE, 133(11), 880-888.

Teizer, J., Cheng, T., and Fang, Y. 2013. Location tracking and data visualization technology to advance construction ironworkers' education and training in safety and productivity. Automation in Construction, 35, 53-68.

Torrent, D. G. and Caldas, C. H. 2009. Methodology for automating the identification and localization of construction components on industrial projects. Journal of Computing in Civil Engineering ASCE, 23(1), 3-13.

Turkan, Y., Bosché, F., Haas, C. T., and Haas, R. 2012a. Automated progress tracking using 4D schedule and 3D sensing technologies. Automation in Construction, 22, 414-421.

Turkan, Y., Bosché, F., Haas, C. T., and Haas, R. 2012b. Toward automated earned value tracking using 3D imaging tools. Journal of Construction Engineering and Management ASCE, 139(4), 423-433.

Vähä, P., Heikkilä, T., Kilpeläinen, P., Järviluoma, M., and Gambao, E. 2013. Extending automation of building construction-Survey on potential sensor technologies and 
robotic applications. Automation in Construction, 36, 168-178.

Vanlande, R., Nicolle, C., and Cruz, C. 2008. IFC and building lifecycle management. Automation in Construction, 18(1), 70-78.

Wang, X., Love, P. E., Kim, M. J., Park, C. S., Sing, C. P., and Hou, L. 2013. A conceptual framework for integrating building information modeling with augmented reality. Automation in Construction, 34, 37-44.

Wang, X., Truijens, M., Hou, L., Wang, Y., and Zhou, Y. 2014a. Integrating Augmented Reality with Building Information Modeling: Onsite construction process controlling for liquefied natural gas industry. Automation in Construction, 40, 96-105.

Wang, X., Yung, P., Luo, H., and Truijens, M. 2014b. An innovative method for project control in LNG project through 5D CAD: A case study. Automation in Construction, 45, 126-135.

Xie, H., Shi, W., and Issa, R. R. 2011. Using rfid and real-time virtual reality simulation for optimization in steel construction. Journal of Information Technology in Construction (ITcon), 16, 291-308.

Xiong, X., Adan, A., Akinci, B., and Huber, D. 2013. Automatic creation of semantically rich 3D building models from laser scanner data. Automation in Construction, 31, 325-337.

Yeh, K. C., Tsai, M. H., and Kang, S. C. 2012. On-site building information retrieval by using projection-based augmented reality. Journal of Computing in Civil Engineering ASCE, 26(3), 342-355.

Zhang, C. and Arditi, D. 2013. Automated progress control using laser scanning technology. Automation in Construction, 36, 108-116.

Zhou, Y., Ding, L. Y., and Chen, L. J. 2013. Application of 4D visualization technology for safety management in metro construction. Automation in Construction, 34, 25-36.

Zhu, Z. and Brilakis, I. 2009. Comparison of optical sensor-based spatial data collection 
techniques for civil infrastructure modeling. Journal of Computing in Civil Engineering ASCE, 23(3), 170-177. 


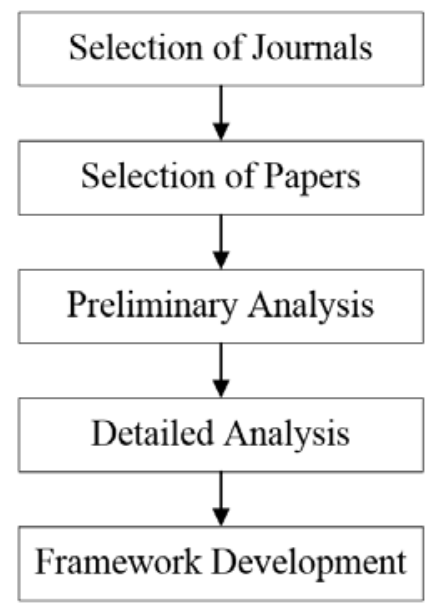

Fig. 1 Processes to develop the BBB conceptual framework 


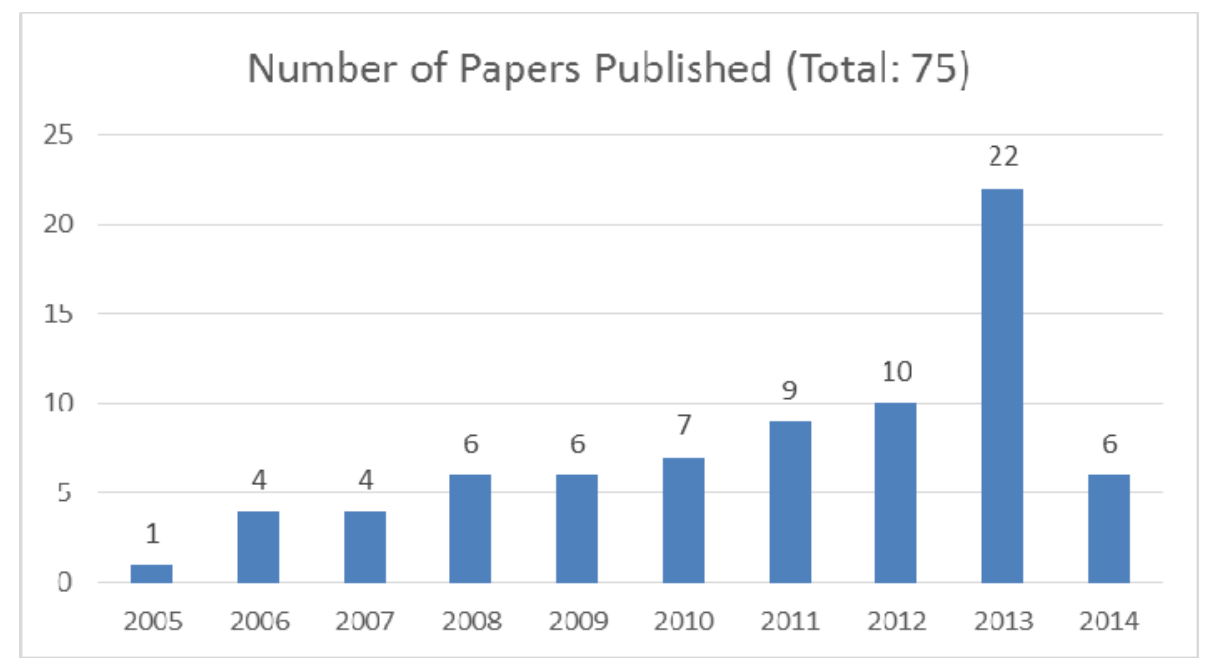

Fig. 2 Distribution of selected papers in the past decade 


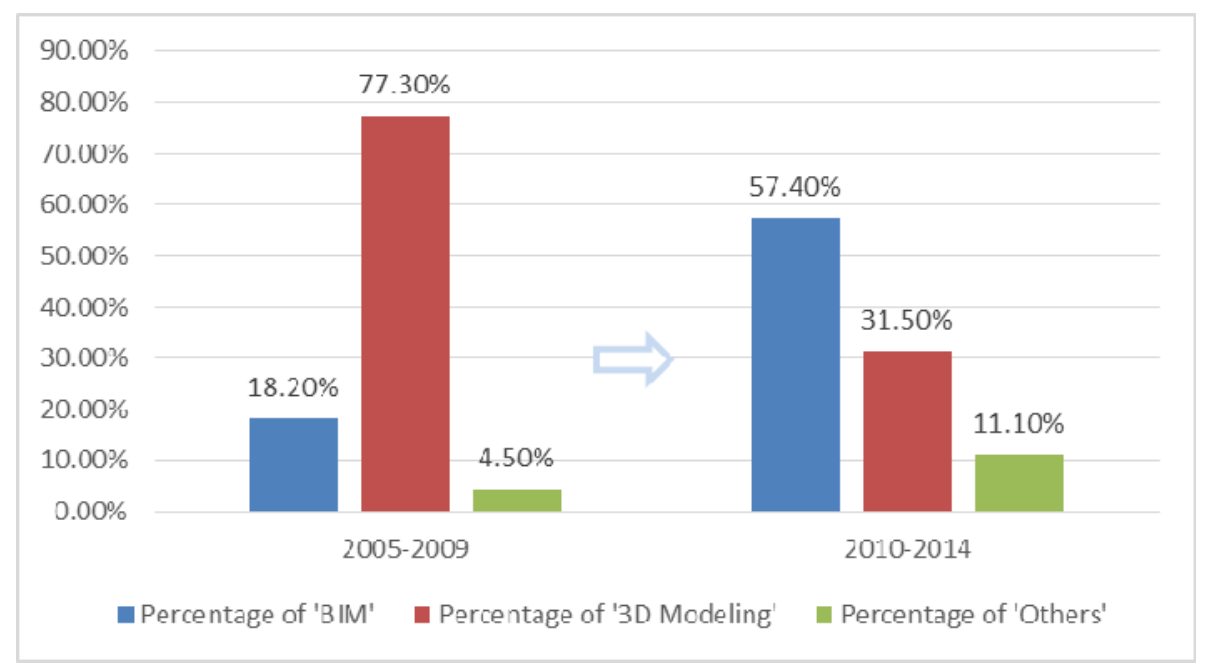

Fig. 3 Percentage of adopted terms from 2005-2009 and 2010-2014 


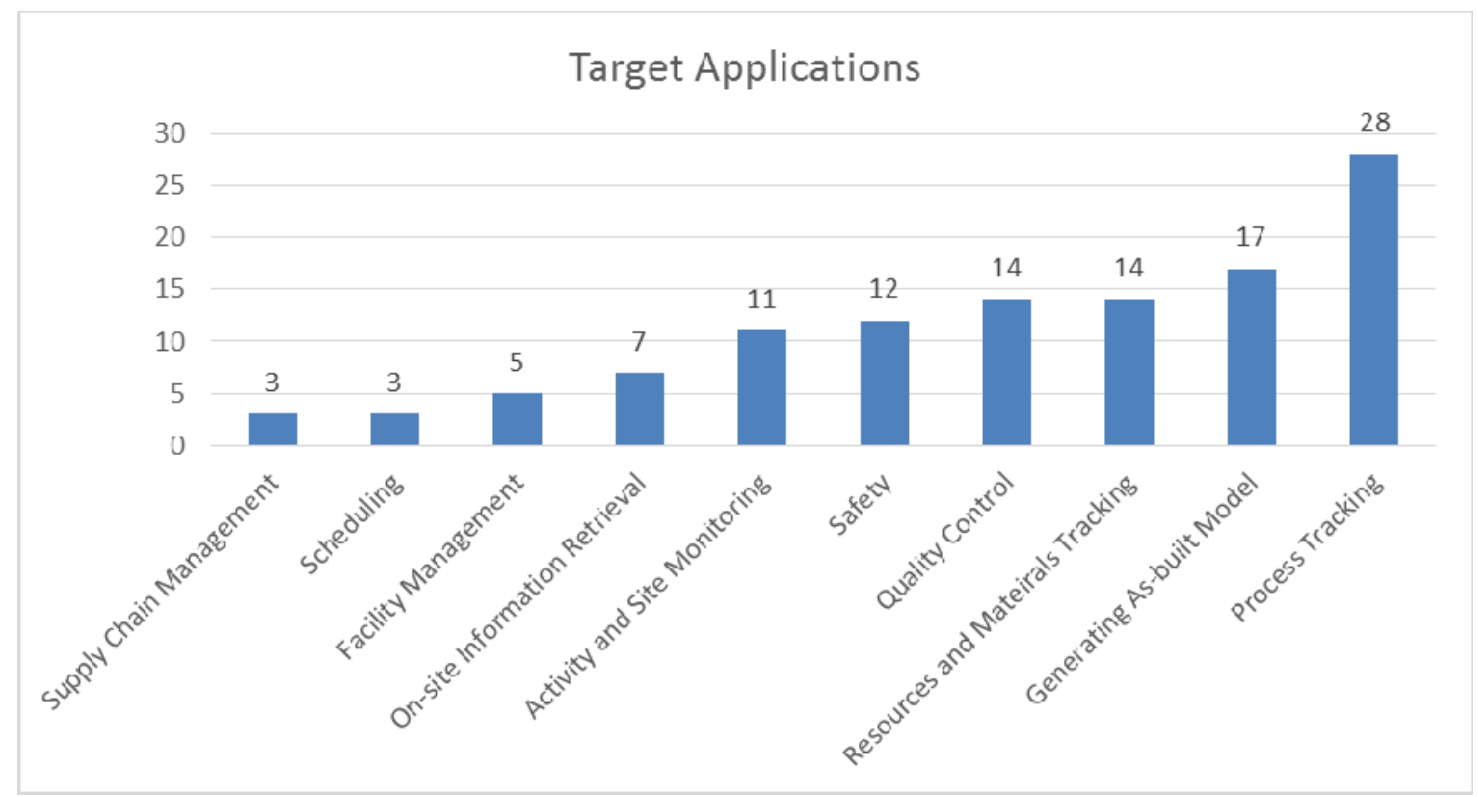

Fig. 4 Distribution of target applications of BBB 


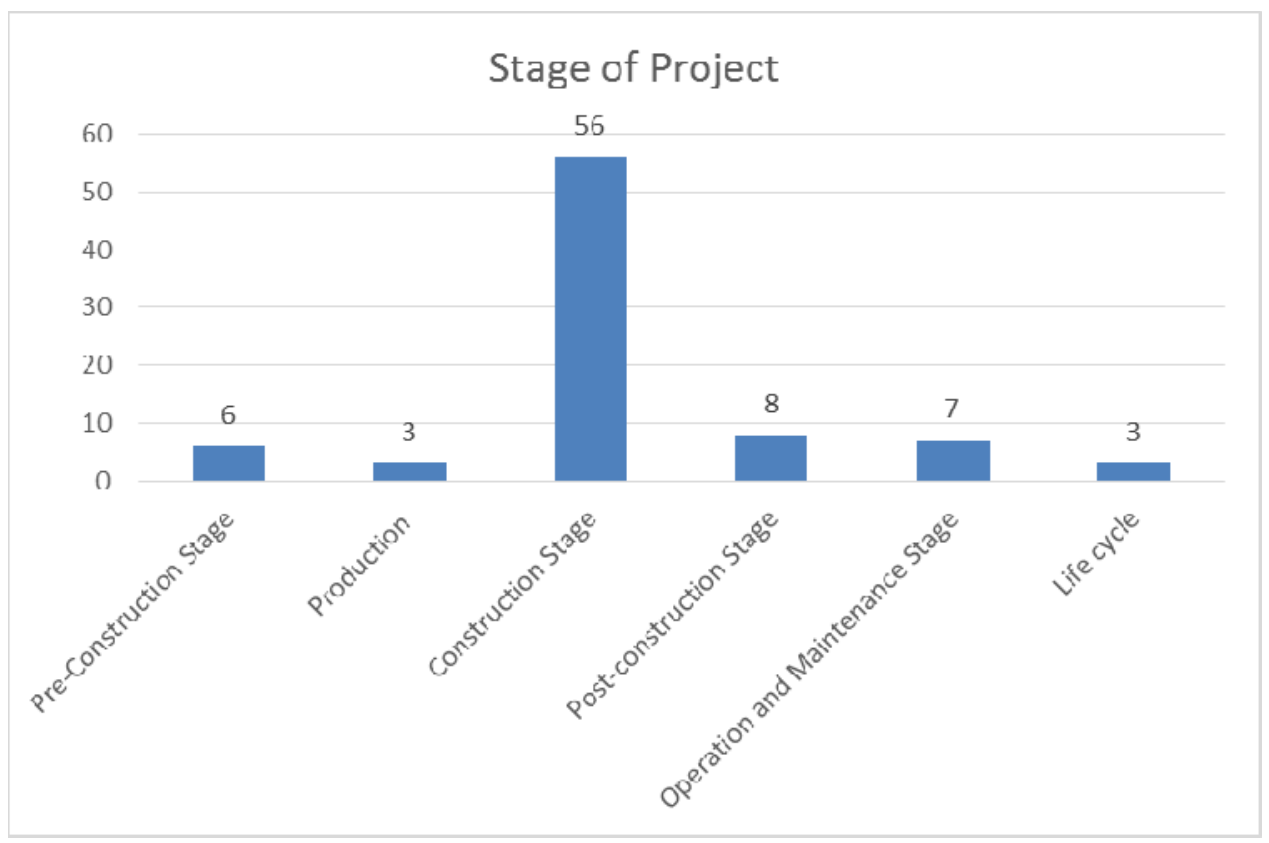

Fig. 5 Project stages for BBB applications 


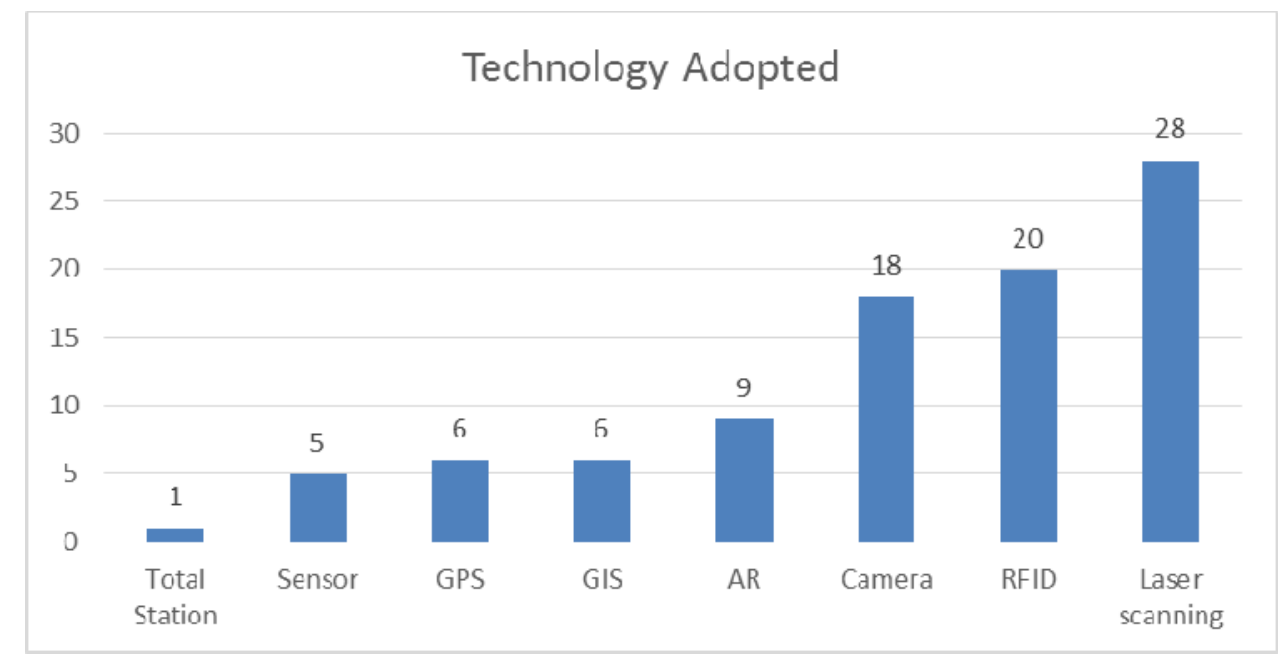

Fig. 6 Technologies adopted 


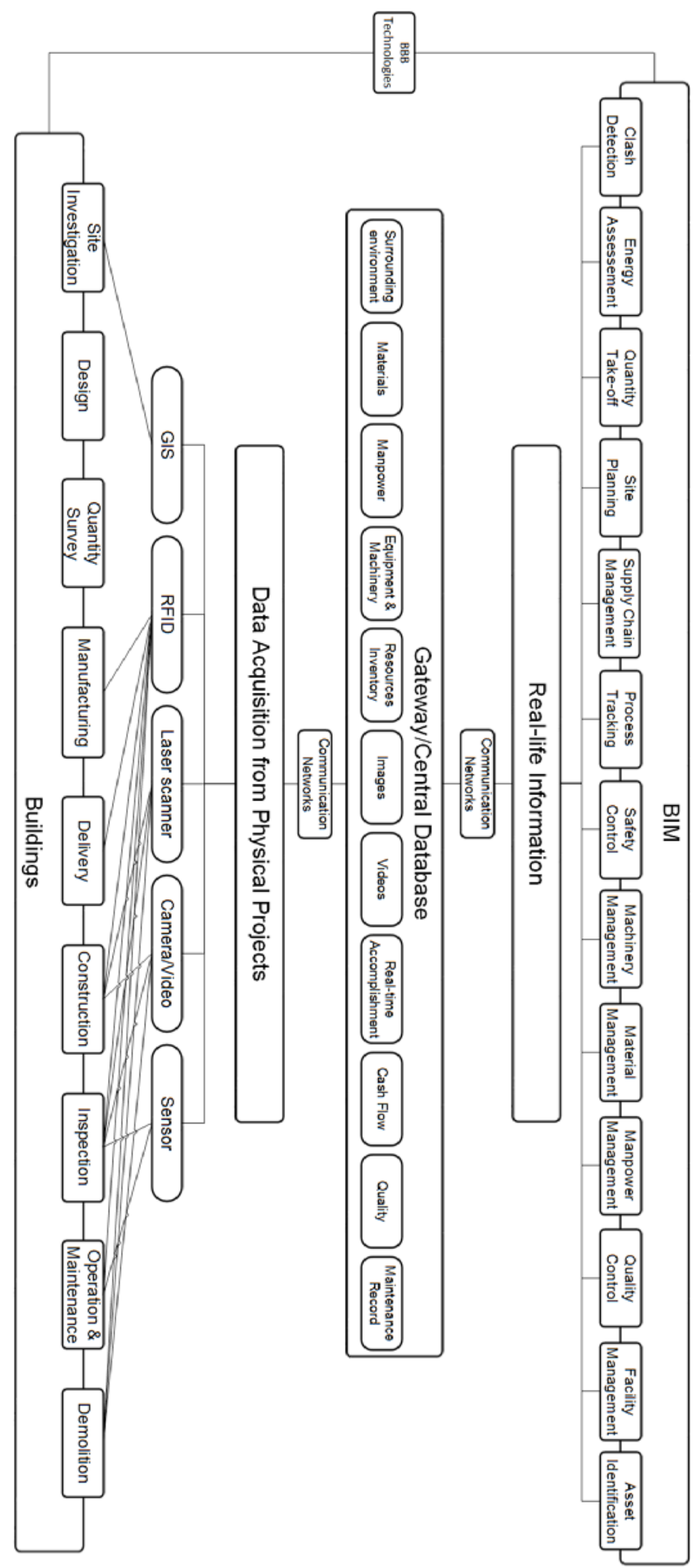

Fig. 7 The conceptual framework for bridging BIM and building 

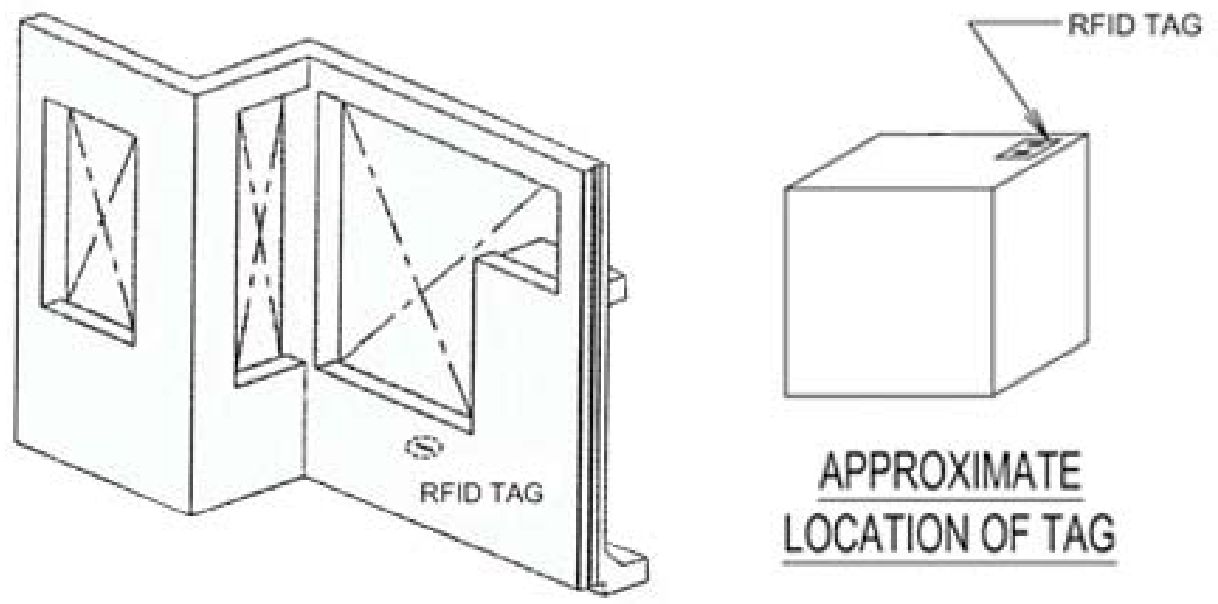

Fig. 8 Building components with RFID tags 
Table 1 Applications of laser scanning

\begin{tabular}{|l|c|c|c|c|c|c|}
\hline & $\begin{array}{l}\text { Process } \\
\text { Tracking }\end{array}$ & $\begin{array}{l}\text { Generating } \\
\text { 'as-built' Model }\end{array}$ & $\begin{array}{l}\text { Quality } \\
\text { Control }\end{array}$ & $\begin{array}{l}\text { Activity and Site } \\
\text { Monitoring }\end{array}$ & Safety & $\begin{array}{l}\text { Resources and } \\
\text { Materials Tracking }\end{array}$ \\
\hline $\begin{array}{l}\text { Laser } \\
\text { Scanning }\end{array}$ & 15 & 12 & 7 & 3 & 2 & 2 \\
\hline
\end{tabular}


Table 2 Applications of RFID

\begin{tabular}{|c|c|c|c|c|c|c|c|}
\hline & $\begin{array}{l}\text { Resources and } \\
\text { Materials } \\
\text { Tracking }\end{array}$ & $\begin{array}{l}\text { Process } \\
\text { Tracking }\end{array}$ & Safety & $\begin{array}{l}\text { Quality } \\
\text { Control }\end{array}$ & $\begin{array}{l}\text { Activity and } \\
\text { Site monitoring }\end{array}$ & $\begin{array}{l}\text { Facility } \\
\text { Management }\end{array}$ & $\begin{array}{l}\text { Supply } \\
\text { Chain } \\
\text { Management }\end{array}$ \\
\hline RFID & 11 & 9 & 4 & 4 & 3 & 3 & 2 \\
\hline
\end{tabular}


Table 3 Applications of camera

\begin{tabular}{|l|c|c|c|c|}
\hline & Process Tracking & Generating ‘as-built’ Model & Activity and Site Monitoring & Safety \\
\hline Camera & 8 & 6 & 3 & 2 \\
\hline
\end{tabular}

